\title{
Selection the optimum place of FACTS devices using fuzzy control system
}

\author{
Jawad Hamad Hameed, Hameed Ali Mohammed, Amer T. Saeed \\ Department of Petroleum Systems Control Engineering, College of Petroleum Processes Engineering \\ Tikrit University, Iraq
}

\begin{tabular}{|c|c|}
\hline Article Info & ABSTRACT \\
\hline Article history: & \multirow{11}{*}{$\begin{array}{l}\text { In this paper, the voltage stability of the power system is studied during fault } \\
\text { conditions. Enhancement of the system's stability will be achieved by } \\
\text { utilizing Flexible AC transmission systems (FACTS) controllers at the best } \\
\text { place in the system. The optimum placement of FACTS controllers occurred } \\
\text { on the most affected bus by the fault in the system (weakest bus). Two } \\
\text { approaches have been used in this study to effectively obtain the best } \\
\text { location of the FACTS controllers in the system. The first method is based on } \\
\text { computing the deviation which occurs in the active power and reactive power } \\
\text { due to the fault at each load bus at a time. Whereas the second method is } \\
\text { performed through exploiting a MATLAB fuzzy set technique utilizing two } \\
\text { indices: Line Flow Index (LFI) and Voltage Profile Index (VPI) during fault } \\
\text { and steady-state conditions. The results show that both of these indices } \\
\text { resulted in the same bus as the best location. Remedial actions in the attempt } \\
\text { at improving in the stability of the power system are discussed taking } \\
\text { the advantage of using FACTS compensation SVC and STATCOM at the } \\
\text { most vulnerable system buses. In this work, MATLAB program with an } \\
\text { IEEE } 24 \text { bus system is examined. }\end{array}$} \\
\hline Received Jan 13, 2020 & \\
\hline Revised Apr 26, 2020 & \\
\hline Accepted Jun 24, 2020 & \\
\hline Keywords: & \\
\hline & \\
\hline Fuzzy control systems & \\
\hline LFI & \\
\hline STATCOM & \\
\hline SVC & \\
\hline VPI & \\
\hline
\end{tabular}

This is an open access article under the CC BY-SA license.

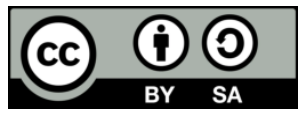

\section{Corresponding Author:}

Jawad Hamad Hameed,

Department of Petroleum Systems Control Engineering,

College of Petroleum Processes Engineering,

Tikrit University, Iraq.

Email: jawad20072003@gmail.com

\section{INTRODUCTION}

In current years, due to the fact that increasing of power demand and limiting the expansion of the power generating units and transmission lines because of environmental and economic reasons, several transmission lines are reaching to their limits and the power systems enter to instability problems. In principle, the electrical system must deliver trustworthy power to the consumer, therefore the reliability of the system must be improved by transferring the power to places of use. Numerous developed methods have been launched in terms of a support system. As a result, system stability becomes a very challenging problem that must be considered [1-3]. The voltage stability analysis is crucial issues because unstable voltage leads to the complete or partial interruption of the power system. Also, the Reactive power plays a significant role in the constancy of the power system $[4,5]$. The failure of the power system to encounter the demands reactive power in the high load systems, it is one of the main reasons for the instability of voltages in the system. The only way to solve these problems is to decrease reactive power load or increase extra reactive power before reaching to collapse point $[6,7]$. Recently with the evolution in control theory, in addition to the electronic revolution witnessed by the world, which have allowed the design and implementation modern 
controllers known as Flexible A.C Transmission System (FACTS). The FACTS controllers are primarily employed for solving numerous power system control problems. However, modern studies show that the possibilities of employing FACTS controllers to develop power system stability in supplement to their core function of power flow control. Also, FACTS devices could be used to improve voltage profile, power transmission capacity, and enhancing power system stability which is a suitable control strategy to enhance different system performances such oscillations, losses of the system, stability, reliability, security, and power factor in distribution systems [1, 8-10]. Although the FACTS controllers are expensive, they provide a and fast and smooth response to provide stability for the power system during the transient and steady-state and allow utilities to run their transmission schemes even nearer to their physical limits, compared with conventional methods [11-13]. The location of FACTS controllers on the power system are very important factor during stability improvement of the system. There are numerous techniques for locating FACTS devices such as contingency sensitivity index (CSI), Genetic Algorithm (GA), sensitivity index, line outage distribution factor (LODF), and Particle Swarm Optimization (PSO) [14-16]. In order to improve the voltage profile in the buses- reactive and active power under diverse loading circumstances-, FACTS devices with a fuzzy system can be used as static controller which leads to advance the stability in power electrical systems [17]. To achieve the stability, security requirement, controllability and maximum system loadability in a transmission line of the system are achieved by an optimal logic fuzzy PID, and genetic algorithm (GA) controller is designed for Thyristor based FACTS controller [18]. In [19], Genetic Algorithm (GA) is utilized to find the optimal location of FACTS device based on MATLAB program for satisfying the stability of the system. In [20, 21], Gravitational search algorithm (GSA) optimization methods is presented for selecting the optimal location.

The aim of this paper is to select the best location of the FACTS controllers on the power system to expand the performance and stability of the system during the steady state and transient state. There are two methods will be used to get the optimum location of the FACTS: the first method is based on the computing the deviation occurs on the active power and reactive power at load buses due to the fault at each load bus at the same time, where the bus has the highest deviation will be considered the weakest bus while the bus has least deviation is considered the most robust bus. The bus that is most affected during the fault and has the highest deviation is considered the weakest bus and the optimum placement for FACTS controller in the system. The first method is called the traditional method, which is occur only during transient state condition (fault). However, the second method is intelligent method, achieved by using a MATLAB fuzzy set technique which are used two indices: Voltage Profile Index (VPI and Line Flow Index (LFI). It depends on the value of $\mathrm{CI}$ index, where the bus which has the highest $\mathrm{CI}$ value is ranking the first and considered the weakest bus, also it is considered the best location of the FACTS devices in the system. This method can be used during steady-state and transient state (fault) as will be described in the next section.

\section{FACTS ALLOCATION METHODOLGIES}

\subsection{Traditional optimum FACTS allocation methodology}

This method is called a traditional method. It is based on computing the deviation occurs in the parameters of each load bus (active power and reactive power) due to the fault at each load bus one at a time. The deviation of these parameters can be computed by (1) and (2) below, where the load bus that has the highest deviation will be considered the weakest bus and the perfect place for FACTS devices. This method can be used during the fault condition only.

$$
\begin{aligned}
& \Delta \mathrm{P}=\mathrm{P}_{\text {fault }}-\mathrm{P}_{\text {base }} \\
& \Delta \mathrm{Q}=\mathrm{Q}_{\text {fault }}-\mathrm{Q}_{\text {base }}
\end{aligned}
$$

where:

$\Delta \mathrm{P}, \Delta \mathrm{Q}$ are active power and reactive power deviation respectively.

$\mathrm{P}_{\text {fault, }}, \mathrm{Q}_{\text {fault }}$ are active power in MW and reactive power in MVar during the fault.

$\mathrm{P}_{\text {base }}, \mathrm{Q}_{\text {base }}$ are active power in MW and reactive power in MVar pre fault during steady-state condition

\subsection{Fuzzy optimum FACTS allocation methodology}

A fuzzy logic controller is influential tool for regulating complex processes and able to clarify the complicated issues without the necessity of a detailed statistical model of the system. The durability of the varying network specifications is another merit of the fuzzy logic controller [22, 23]. In this method, they are adopted two indices LFI and VPI, that correspond to the margin of voltage stability for a selected operational condition. The initial index is the "Line Flow Index" (LFI) that identified by (3) below, the derivation at: 
$\mathrm{LFI}=\frac{2 \mathrm{P}_{\mathrm{r}}[1+\cos (\theta-\Phi)]}{\mathrm{Vs}^{2} \mathrm{Y} \cos (\Phi)}$

When (LFI) is near to unity, that means the maximum loadability point is reached, after this point, the system becomes critical [24-26]. By utilizing fuzzy setting within the MATLAB model program, LFI is classified into five curves (memberships) to characterize the input of the fuzzy laws as shown in Figure 1. The output rules of fuzzy are representing the impact of line flow either due to a high load during steady-state or due to fault during the transient state, and it is known as "Severity Index of Line Flow" (SILF). SILF is also classified into five curves (memberships) as shown in Figure 2. The voltage in p.u. at load buses of the system is the second index, and it is described "Voltage Profile Index" (VPI) as shown in Figure 3. The VPI supplied to the rules of fuzzy as four input curves (memberships) to give the fuzzy output which call "Severity Index of Voltage Profiles" (SIVP). It is classified into five curves (memberships) as shown in Figure 4. Can be determined the most vulnerable system buses by Criticality Index (CI), which computes by summation the two severity indices SILF and SIVP. According to CI value will be able to determine the weakest bus then ranking all load buses. Where the bus which has the highest CI value is ranked the first and considered it the weakest bus. In the Figures 1- 4, the symbols that mean: Small index (S), Very Small index (VS), Medium index (M), Very High index (VH), High index (H), Low Severity (LS), Very Low Severity (VLS), Above Severity (AS), Below Severity (BS), More Severity (MS), Normal Voltage (NV), Medium voltage (MED), Low Voltage (LV), Over Voltage (OV), PRE-Severity (PRES), More Severity (MOS) and Medium Severity (MEDS).

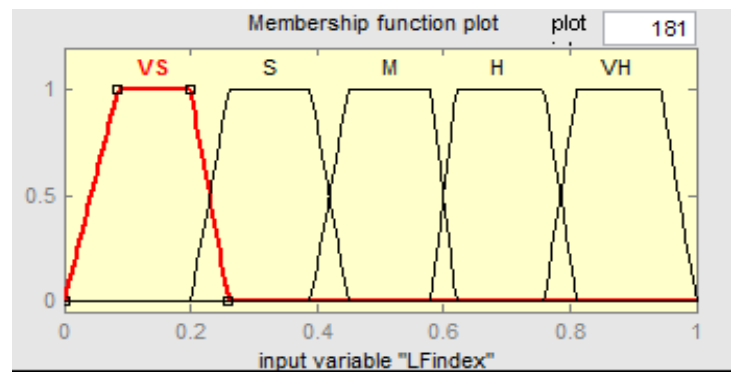

Figure 1. LFI curves

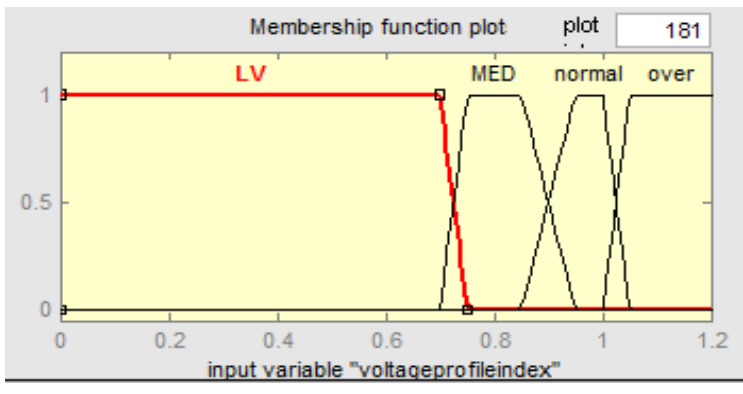

Figure 3. VPI curves

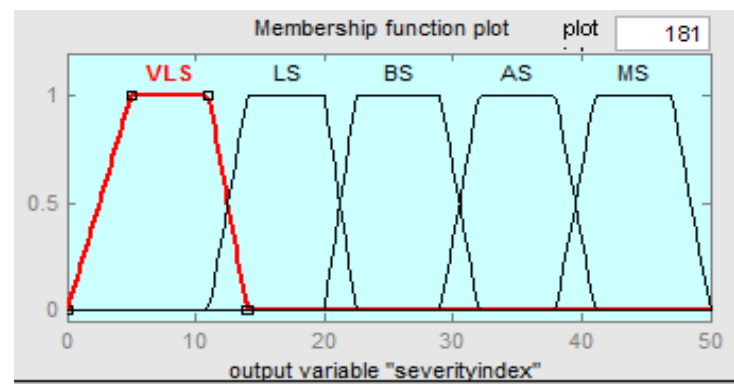

Figure 2. SILF curves

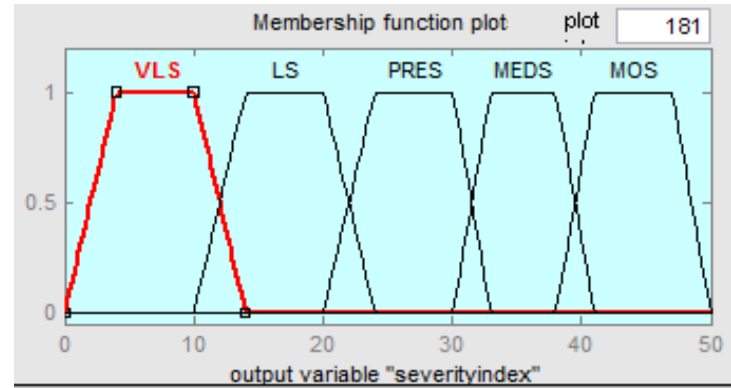

Figure 4. SIVP curves

The proposed method is explained in the next steps:

- $\quad$ Selecting load bus one by one (one at a time), reactive power demand is increased until LFI reaches to the extreme value.

- $\quad$ Calculating LFI and VPI.

- $\quad$ LFI and VPI are fed in fuzzy set notation to give SILF and SIVP by using fuzzy rules, then calculate CI for each load bus by (4) below.

$$
\mathrm{CI}=\sum \mathrm{SILF}+\sum \mathrm{SIVP}
$$

- $\quad$ Repeating the above steps for each load bus. 
- $\quad$ Ranking all the buses descending based on the value of the CI for each load bus, where the most significant value of $\mathrm{CI}$ is the bus being the weakest.

- During the fault conditions, the steps from step2 to step5 will be repeated. By assuming the fault influence on load buses is similar to the severity which occurs on load buses during maximum loadability.

\section{RESULTS AND DISCUSSION}

In this paper, IEEE 24 bus system will be used. The buses of the system are connected by transmission lines. Bus13 is a slack bus, buses $(1,2,7,14,15,16,18,21,22$ and 23) are PV buses and buses $(3,4,5,6,8,9,10,19$ and 20) are load buses. The system has 11 generations, 9 loads; each one has active MW and reactive power MVar and 38 transmission lines as explained in Figure 5.

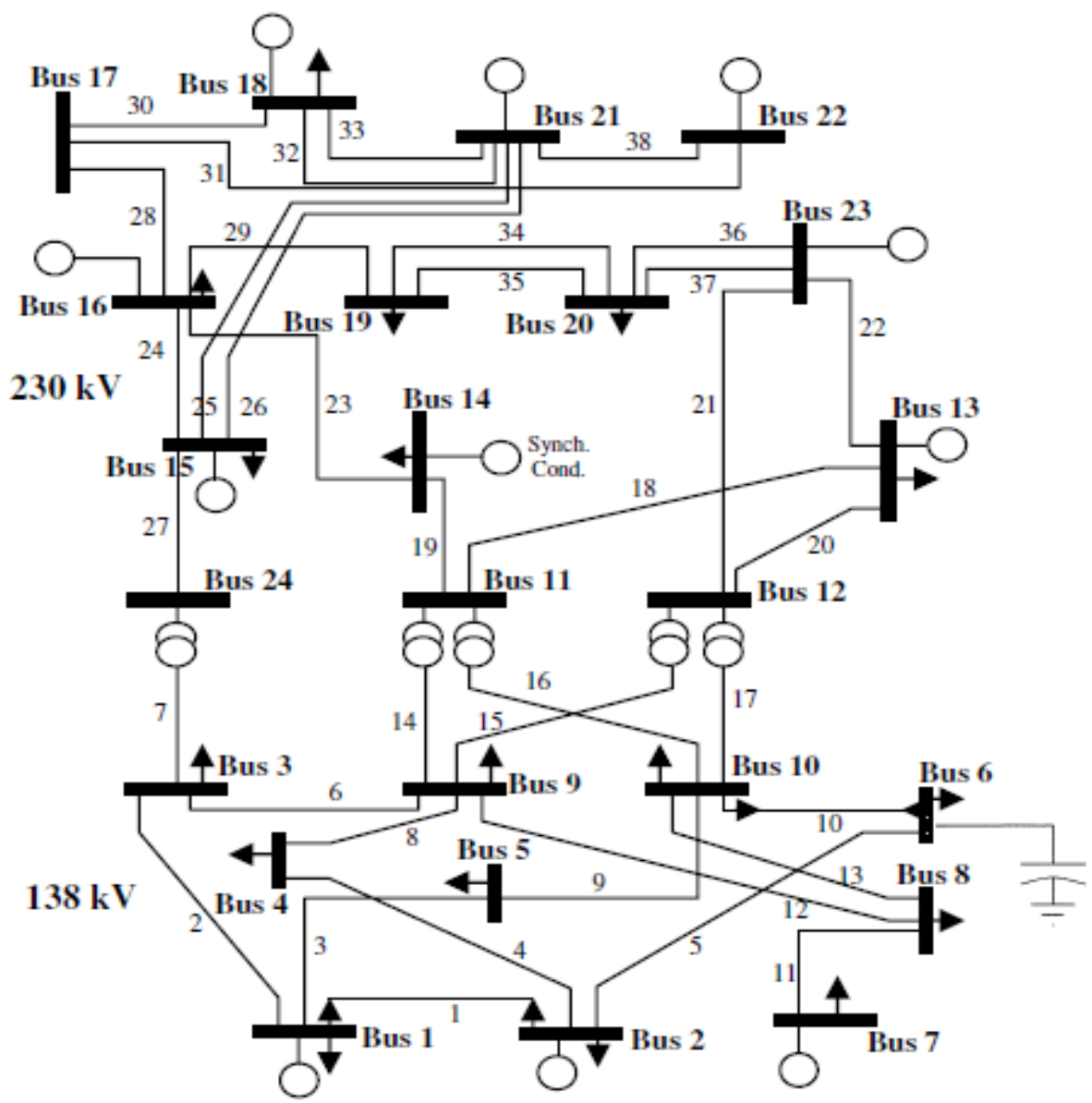

Figure 5. Single line diagram of IEEE 24-bus system

\subsection{Steady-state results}

MATLAB simulation results during steady-state will be demonstrated in Table 1 below. These results represent Voltage (Vin p.u), Active power and Reactive power values at each bus in the system during steady state. To determine the optimum placement of the FACTS devices, the intelligent method will be used, achieved by using a MATLAB fuzzy set technique where, LFI and VPI will be calculated at each load bus, one at a time, during the severest loading condition (high load point). Then, the two inputs LFI and VPI, for each load bus, are fed into fuzzy rules to give SILF and SIVP respectively. By summing SILF and SIVP will be getting to $\mathrm{CI}$ for each load bus during high load point to control the weakest bus and rank the load buses according to CI value from high to low value as shown in Table 2.

Table 2 is demonstrated the CI value of each load bus, then ranking the load buses based on its value. Therefore Bus 9 is ranked at first and it is considered the weakest bus, because it has the biggest CI 
value. Then, it is selecting as the suitable placement for SVC and STATCOM device to enhance the stability of the system

Table 1. Steady-state load flow

\begin{tabular}{cccc}
\hline Bus no. & P [MW] & Q [Mvar] & Voltage [p.u] \\
\hline 1 & -89.27 & -766 & 1.035 \\
2 & -99.4 & -195.1 & 1.035 \\
3 & 204.3 & -241.9 & 0.9281 \\
4 & 36.25 & 88.15 & 0.9439 \\
5 & -12.9 & -164.4 & 0.94 \\
6 & -78.45 & -44.82 & 0.8644 \\
7 & 63.55 & 342.4 & 1.025 \\
8 & -404.4 & -53.56 & 0.9448 \\
9 & -298.1 & 344.3 & 0.8973 \\
10 & -291.2 & 293 & 0.8513 \\
11 & -289.4 & 76.26 & 1.01 \\
12 & -301.2 & 66.3 & 1.03 \\
13 & 197.2 & -14.32 & 1.02 \\
14 & 378.9 & -24.24 & 0.9881 \\
15 & -225.8 & -124.1 & 1.014 \\
16 & 188.3 & -43.93 & 1.017 \\
17 & -338.6 & -81.08 & 1.035 \\
18 & -62.93 & -104.4 & 1.05 \\
19 & -182.3 & -19.25 & 1.024 \\
20 & -137.5 & -18.64 & 1.039 \\
21 & -399.9 & -124.8 & 1.05 \\
22 & -299.9 & 21.86 & 1.05 \\
23 & -364.6 & -110.4 & 1.05 \\
24 & -204.6 & 8.668 & 1 \\
\hline & & &
\end{tabular}

Table 2. CI and ranking during steady-state

\begin{tabular}{ccc}
\hline Bus no. & CI $=\sum$ SIVP $+\sum$ SILF & Rank \\
\hline 9 & 1034.2 & 1 \\
3 & 1032.09 & 2 \\
6 & 1022.79 & 3 \\
10 & 1010.18 & 4 \\
5 & 1003.25 & 5 \\
4 & 986.44 & 6 \\
8 & 939.81 & 7 \\
19 & 906.14 & 8 \\
20 & 898.13 & 9 \\
\hline
\end{tabular}

\subsection{Results during fault (Transient State)}

Applying three phase faults at system load buses, one at a time, during $0.3 \mathrm{sec}$ without inserting any compensation components. During these conditions, will be flow the two methods: intelligent MATLAB fuzzy method and traditional method to determine the optimum location of FACTS devices. Now by fuzzy methodology the LFI and VPI will be also calculating, and they are also fed into fuzzy rules to give fuzzy outputs indices SILF and SIVP respectively. Summation of this indices will be resulted CI for each load bus, the load buses will be ranked depending on the CI value for each load bus, and the bus which has the highest value considered the best location of the FACTS devices and the weakest bus in the system as demonstrated in Table 3.

From the obtained results, as shown in Table 3, Bus 9 is ranked at first because it has the highest CI value, therefore it considered the weakest bus, whereas Bus 20 is ranked at last because it has the lowest CI value, therefore, it is considered strongest one. Therefore, Bus 9 is the optimum location of SVC and STATCOM controllers. Based on traditional method during fault occurred at load buses respectively, then computing the deviation value occurs in the parameters of each load bus (active and reactive power) by using (1) and (2) of $\Delta \mathrm{P}, \Delta \mathrm{Q}$ at Bus 9 has highest deviation, while Bus 20 has a value of the least deviation as shown in Figure 6 , Figure 7 and Table 4 , Table 5 below. That means Bus 9 is the most vulnerable bus and it is the best placement for SVC and STATCOM controllers.

Table 3. CI and rank during fault condition

\begin{tabular}{ccc}
\hline Bus no. & CI $=\sum$ SIVP $+\sum$ SILF & Rank \\
\hline 9 & 919.86 & 1 \\
3 & 919.65 & 2 \\
10 & 918.29 & 3 \\
19 & 918.12 & 4 \\
6 & 918.09 & 5 \\
4 & 917.96 & 6 \\
5 & 917.47 & 7 \\
8 & 917.24 & 8 \\
20 & 906.14 & 9 \\
\hline
\end{tabular}


From the results, as shown in Figure 6 and Table 4, noted the highest active power Deviation $(\Delta \mathrm{P})$ occur in Bus 9, while Bus 20 has a value of the least active power Deviation $\Delta \mathrm{P}$. That means Bus 9 is the most vulnerable bus and it is the best placement for SVC and STATCOM devices.

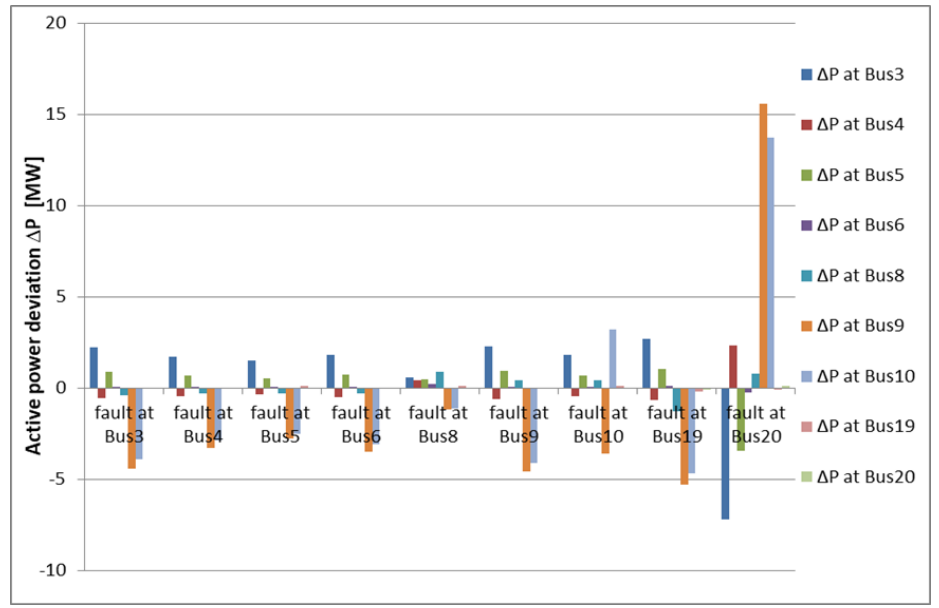

Figure 6. $\Delta \mathrm{P}$ in MW due to fault at load buses respectively

Table 4. $\Delta \mathrm{P}$ in MW due to fault at load buses respectively

\begin{tabular}{llllllllll}
\hline Bus no. & \multicolumn{6}{c}{ Active } & power deviation & $(\triangle \mathrm{P}=\mathrm{P}$ fault $-\mathrm{Pbase})[\mathrm{MW}]$ & \multicolumn{6}{c}{ during fault at: } \\
& Bus3 & Bus4 & Bus5 & Bus6 & Bus8 & Bus9 & Bus10 & Bus19 & Bus20 \\
\hline 3 & +2.2 & +1.7 & +1.5 & +1.8 & +0.6 & +2.3 & +1.8 & +2.7 & -7.2 \\
4 & -0.58 & -0.47 & -0.37 & -0.49 & +0.41 & -0.62 & -0.46 & -0.64 & +2.33 \\
5 & +0.87 & +0.7 & +0.53 & +0.72 & +0.48 & +0.93 & +0.69 & +1.05 & -3.47 \\
6 & +0.06 & +0.06 & +0.03 & +0.04 & +0.21 & +0.07 & +0.04 & +0.09 & -0.26 \\
8 & -0.4 & -0.3 & -0.3 & -0.3 & +0.9 & +0.4 & +0.4 & -1.3 & +0.8 \\
9 & -4.4 & -3.3 & -2.8 & -3.5 & -1.2 & -4.6 & -3.6 & -5.3 & +15.6 \\
10 & -3.9 & -2.9 & -2.5 & -3.1 & -1.1 & -4.1 & +3.2 & -4.7 & +13.7 \\
19 & 0 & 0 & +0.1 & 0 & +0.1 & 0 & +0.1 & -0.2 & -0.1 \\
20 & 0 & 0 & 0 & 0 & 0 & 0 & 0 & -0.1 & +0.1 \\
\hline
\end{tabular}

From the results, as shown in Figure 7 and Table 5, noted the highest reactive power Deviation $\Delta \mathrm{Q}$ occur in Bus 9, while Bus 20 has a value of the least reactive power Deviation $\Delta \mathrm{Q}$. That means Bus 9 is the most vulnerable bus and it is the best placement for SVC and STATCOM devices. Based on all result, Bus 9 is the best location for SVC and STATCOM devices during steady state and transient state which achieved by intelligent MATLAB fuzzy method and traditional method.

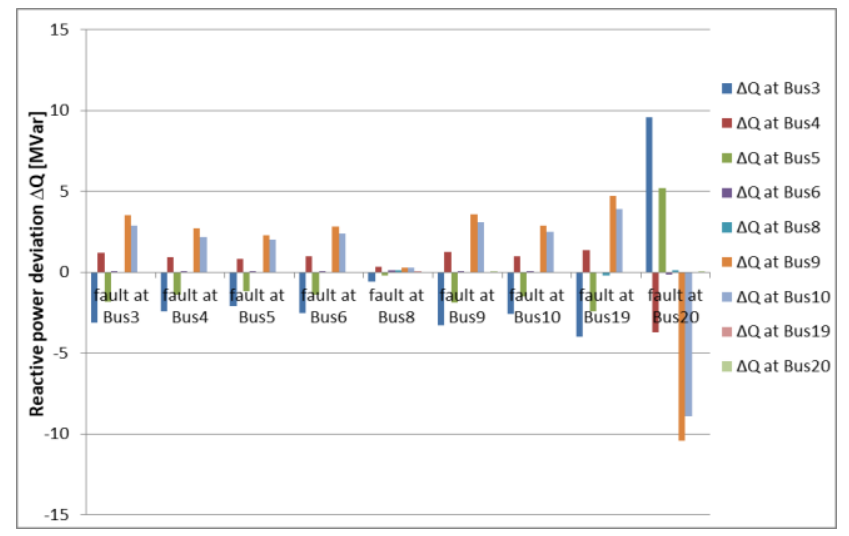

Figure 7. $\Delta \mathrm{Q}$ in MVar due to fault at load buses respectively 
Table 5. $\Delta \mathrm{Q}$ in MVar due to fault at load buses respectively Steady-state load flow

\begin{tabular}{llllllllll}
\hline Bus no. & \multicolumn{6}{c}{ Reactive power deviation } & $(\triangle \mathrm{Q}=$ Qfault - Qbase $)$ [MVar] during fault at: \\
& Bus3 & Bus4 & Bus5 & Bus6 & Bus8 & Bus9 & Bus10 & Bus19 & Bus20 \\
\hline 3 & -3.1 & -2.4 & -2.1 & -2.5 & -0.6 & -3.3 & -2.6 & -4 & +9.6 \\
4 & +1.19 & +0.91 & +0.8 & +0.96 & +0.33 & +1.26 & +0.99 & +1.38 & -3.73 \\
5 & -1.8 & -1.4 & -1.2 & -1.4 & -0.2 & -1.9 & -1.5 & -2.4 & +5.2 \\
6 & +0.03 & +0.03 & +0.02 & +0.03 & +0.12 & +0.03 & +0.02 & -0.06 & -0.15 \\
8 & -0.06 & -0.04 & -0.04 & -0.05 & +0.11 & -0.06 & -0.06 & -0.18 & +0.1 \\
9 & +3.5 & +2.7 & +2.3 & +2.8 & +0.3 & +3.6 & +2.9 & +4.7 & -10.4 \\
10 & +2.9 & +2.2 & +2 & +2.4 & +0.3 & +3.1 & +2.5 & +3.9 & -8.9 \\
19 & 0 & 0 & 0 & 0 & +0.01 & 0 & -0.01 & -0.02 & -0.01 \\
20 & -0.01 & -0.01 & -0.01 & -0.01 & 0 & +0.01 & -0.01 & -0.02 & +0.01 \\
\hline
\end{tabular}

\subsection{FACTS controllers for system stability enhancement}

Applying SVC and STATCOM at each load bus, one at a time, (3, 4, 5, 6, 8, 9, 10, 19 and 20) during fault condition to enhance the stability. For example, the result is taken when fault at bus 8 and applying SVC/STACOM at load buses respectively, then the deviation in active power $\Delta \mathrm{P}$ and reactive power $\Delta \mathrm{Q}$ at the load buses respectively due to the fault at bus 8, shown in Figures (8-11) and Tables (6-9).

From the above data results in the Figures (8-11) and Tables (6-9); during applied of FACTS controllers SVC/STACOM, the deviation in active power $\Delta \mathrm{P}$ and reactive power $\Delta \mathrm{Q}$ at the load buses by the fault, is reducing and it becomes near to zero especially when the SVC/STACOM devices applying in bus 9, that also prove that it is the optimum location of the FACTS devices, therefore the system returns to stability conditions. Also noted from results that the deviation reaches to its minimum and becomes very low incase of using STATCOM as compared to using SVC. In other words, STATCOM is better than SVC in terms of maintaining the stability of the system.

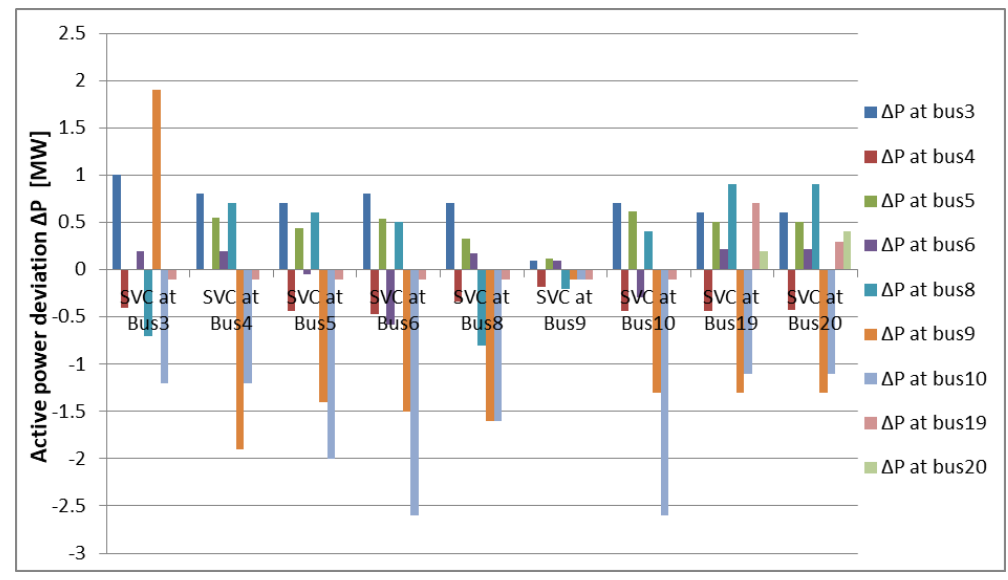

Figure $8 . \Delta \mathrm{P}$ in MW due to fault at bus 8 and $\mathrm{SVC}$ at load buses respectively.

Table 6. $\triangle \mathrm{P}$ in MW during fault at bus 8 and $\mathrm{SVC}$ at load buses respectively

\begin{tabular}{|c|c|c|c|c|c|c|c|c|c|}
\hline SVC at & $\Delta \mathrm{P}$ at bus 3 & $\Delta \mathrm{P}$ at bus 4 & $\Delta \mathrm{P}$ at bus 5 & $\Delta \mathrm{P}$ at bus 6 & $\Delta \mathrm{P}$ at bus 8 & $\Delta \mathrm{P}$ at bus 9 & $\Delta \mathrm{P}$ at bus 10 & $\Delta \mathrm{P}$ at bus 19 & $\begin{array}{l}\Delta \mathrm{P} \text { at } \\
\text { bus } 20\end{array}$ \\
\hline Bus4 & +0.8 & 0 & +0.55 & +0.2 & +0.7 & -1.9 & -1.2 & -0.1 & 0 \\
\hline Bus6 & +0.8 & -0.47 & +0.54 & -0.58 & +0.5 & -1.5 & -2.6 & -0.1 & 0 \\
\hline Bus8 & 0.7 & -0.34 & +0.33 & +0.17 & -0.8 & -1.6 & -1.6 & -0.1 & 0 \\
\hline Bus9 & +0.1 & -0.18 & +0.12 & +0.1 & -0.2 & -0.1 & -0.1 & -0.1 & 0 \\
\hline Bus20 & +0.6 & -0.43 & +0.51 & +0.22 & +0.9 & -1.3 & -1.1 & +0.3 & +0.4 \\
\hline
\end{tabular}




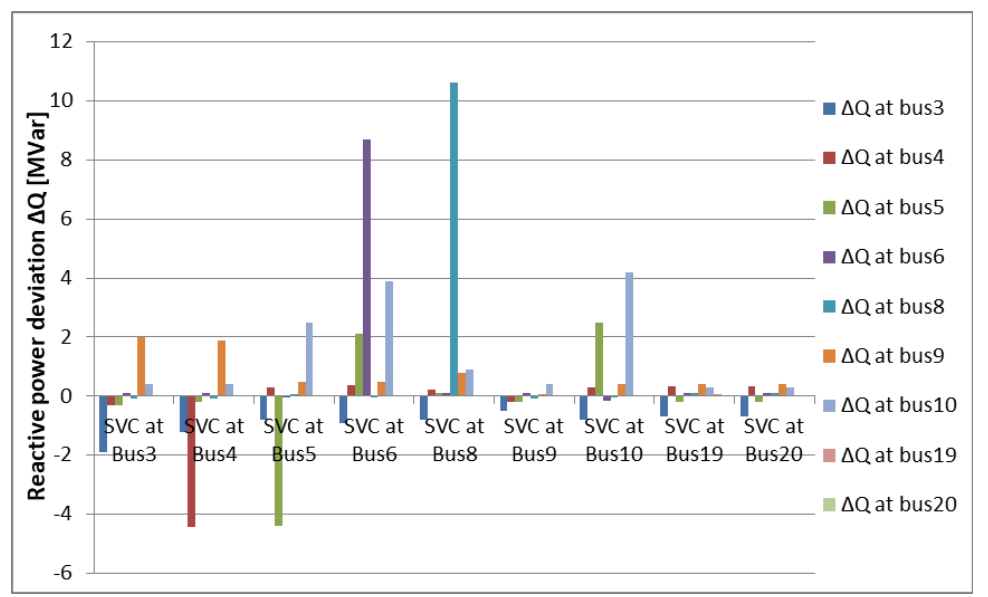

Figure 9. $\Delta \mathrm{Q}$ in MVar due to fault at bus 8 and SVC at load buses, respectively

Table 7. $\Delta \mathrm{Q}$ in MVar during fault at bus 8 and SVC at load buses respectively

\begin{tabular}{|c|c|c|c|c|c|c|c|c|c|}
\hline $\mathrm{VC}$ at & $\begin{array}{l}\Delta Q \text { at } \\
\text { bus3 }\end{array}$ & $\begin{array}{l}\Delta \mathrm{Q} \text { at } \\
\text { bus4 }\end{array}$ & $\begin{array}{l}\Delta Q \text { at } \\
\text { bus5 }\end{array}$ & $\begin{array}{l}\Delta Q \text { at } \\
\text { bus6 }\end{array}$ & $\begin{array}{l}\Delta \mathrm{Q} \text { at } \\
\text { bus8 }\end{array}$ & $\begin{array}{l}\Delta Q \text { at } \\
\text { bus9 }\end{array}$ & $\begin{array}{l}\Delta \mathrm{Q} \text { at } \\
\text { bus } 10\end{array}$ & $\begin{array}{l}\Delta Q \text { at } \\
\text { bus19 }\end{array}$ & $\begin{array}{l}\Delta Q \text { at } \\
\text { bus } 20\end{array}$ \\
\hline Bus3 & -1.9 & -0.31 & -0.3 & +0.1 & -0.09 & +2 & +0.4 & +0.01 & 0 \\
\hline Bus4 & -1.2 & -4.43 & -0.2 & +0.11 & -0.09 & +1.9 & +0.4 & +0.01 & 0 \\
\hline Bus5 & -0.8 & +0.31 & -4.4 & -0.03 & +0.08 & +0.5 & +2.5 & +0.01 & 0 \\
\hline Bus6 & -0.9 & +0.37 & +2.1 & +8.69 & -0.06 & +0.5 & +3.9 & +0.01 & 0 \\
\hline Bus8 & -0.8 & +0.21 & +0.1 & +0.09 & +10.63 & +0.8 & +0.9 & +0.01 & 0 \\
\hline Bus9 & -0.5 & -0.19 & -0.2 & +0.1 & -0.08 & +0.08 & +0.4 & +0.01 & 0 \\
\hline Bus10 & -0.8 & +0.31 & +2.5 & -0.17 & -0.05 & +0.4 & +4.2 & +0.01 & 0 \\
\hline Bus19 & -0.7 & +0.35 & -0.2 & +0.12 & +0.12 & +0.4 & +0.3 & +0.08 & +0.03 \\
\hline Bus20 & -0.7 & +0.35 & -0.2 & +0.12 & +0.12 & +0.4 & +0.3 & +0.04 & +0.04 \\
\hline
\end{tabular}

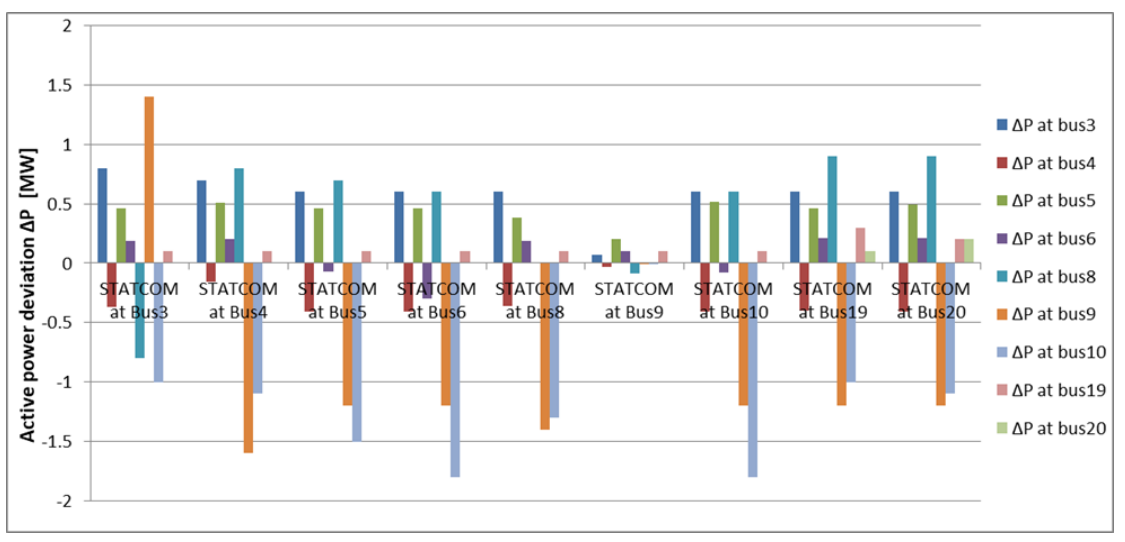

Figure 10. $\triangle \mathrm{P}$ in MW due to fault at bus 8 and STATCOM at load buses, respectively.

Table $8 . \Delta \mathrm{P}$ in MW during fault at bus 8 and STATCOM at load buses, respectively

\begin{tabular}{|c|c|c|c|c|c|c|c|c|c|}
\hline $\begin{array}{c}\text { STATCOM } \\
\text { at } \\
\end{array}$ & $\begin{array}{l}\Delta \mathrm{P} \text { at } \\
\text { bus3 }\end{array}$ & $\begin{array}{l}\Delta \mathrm{P} \text { at } \\
\text { bus4 }\end{array}$ & $\begin{array}{l}\Delta \mathrm{P} \text { at } \\
\text { bus5 }\end{array}$ & $\begin{array}{l}\Delta \mathrm{P} \text { at } \\
\text { bus6 }\end{array}$ & $\begin{array}{l}\Delta \mathrm{P} \text { at } \\
\text { bus8 }\end{array}$ & $\begin{array}{l}\Delta \mathrm{P} \text { at } \\
\text { bus } 9\end{array}$ & $\begin{array}{l}\Delta \mathrm{P} \text { at } \\
\text { bus10 }\end{array}$ & $\begin{array}{l}\Delta \mathrm{P} \text { at } \\
\text { bus19 }\end{array}$ & $\begin{array}{l}\Delta \mathrm{P} \text { at } \\
\text { bus } 20\end{array}$ \\
\hline Bus3 & +0.8 & -0.37 & +0.46 & +0.19 & -0.8 & +1.4 & -1 & +0.1 & 0 \\
\hline Bus4 & +0.7 & -0.16 & +0.51 & +0.2 & +0.8 & -1.6 & -1.1 & +0.1 & 0 \\
\hline Bus5 & +0.6 & -0.41 & +0.46 & -0.07 & +0.7 & -1.2 & -1.5 & +0.1 & 0 \\
\hline Bus6 & +0.6 & -0.41 & +0.46 & -0.3 & +0.6 & -1.2 & -1.8 & +0.1 & 0 \\
\hline Bus8 & 0.6 & -0.36 & +0.38 & +0.19 & 0 & -1.4 & -1.3 & +0.1 & 0 \\
\hline Bus9 & +0.07 & -0.03 & +0.2 & +0.1 & -0.09 & -0.01 & -0.01 & +0.1 & 0 \\
\hline Bus10 & +0.6 & -0.41 & +0.52 & -0.08 & +0.6 & -1.2 & -1.8 & +0.1 & 0 \\
\hline Bus19 & +0.6 & -0.4 & +0.46 & +0.21 & +0.9 & -1.2 & -1 & +0.3 & +0.1 \\
\hline Bus20 & +0.6 & -0.41 & +0.49 & +0.21 & +0.9 & -1.2 & -1.1 & +0.2 & +0.2 \\
\hline
\end{tabular}




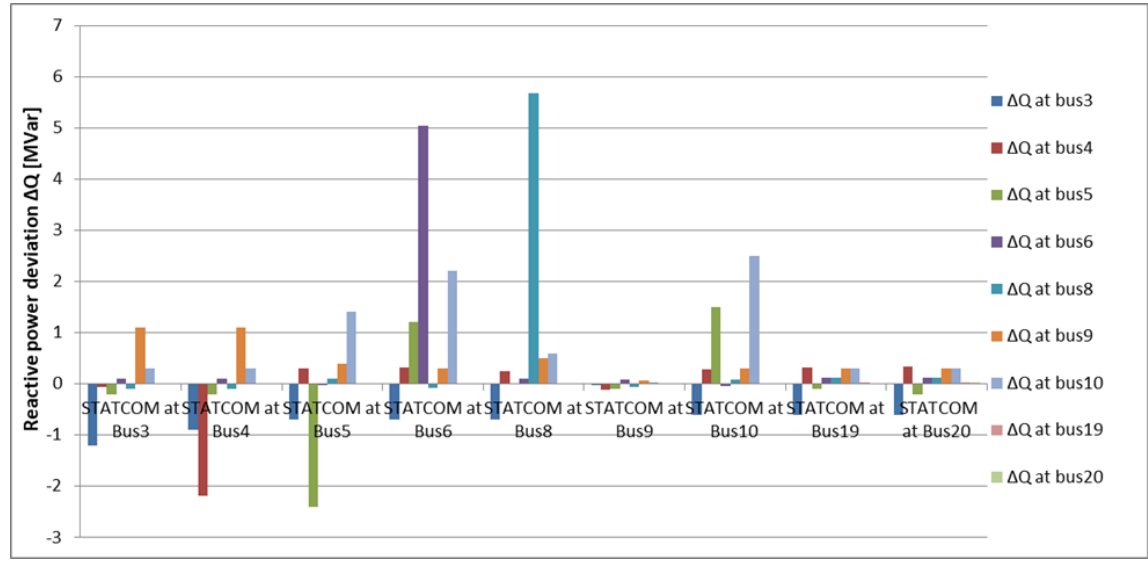

Figure 11. $\Delta \mathrm{Q}$ in MVar due to fault at bus 8 and STATCOM at load buses respectively.

Table 9. $\triangle \mathrm{Q}$ in MVar during fault at bus 8 and STATCOM at load buses respectively

\begin{tabular}{|c|c|c|c|c|c|c|c|c|c|}
\hline $\begin{array}{c}\text { STATCOM } \\
\text { at }\end{array}$ & $\begin{array}{c}\Delta \mathrm{Q} \text { at } \\
\text { bus3 }\end{array}$ & $\begin{array}{c}\Delta \mathrm{Q} \text { at } \\
\text { bus4 }\end{array}$ & $\begin{array}{c}\Delta \mathrm{Q} \text { at } \\
\text { bus5 }\end{array}$ & $\begin{array}{c}\Delta \mathrm{Q} \text { at } \\
\text { bus6 }\end{array}$ & $\begin{array}{c}\Delta \mathrm{Q} \text { at } \\
\text { bus } 8\end{array}$ & $\begin{array}{c}\Delta \mathrm{Q} \text { at } \\
\text { bus } 9\end{array}$ & $\begin{array}{l}\Delta \mathrm{Q} \text { at } \\
\text { bus } 10\end{array}$ & $\begin{array}{l}\Delta \mathrm{Q} \text { at } \\
\text { bus } 19\end{array}$ & $\begin{array}{l}\Delta \mathrm{Q} \text { at } \\
\text { bus } 20\end{array}$ \\
\hline Bus3 & -1.2 & -0.06 & -0.2 & +0.11 & -0.1 & +1.1 & +0.3 & +0.01 & 0 \\
\hline Bus4 & -0.9 & -2.18 & -0.2 & +0.11 & -0.1 & +1.1 & +0.3 & +0.01 & 0 \\
\hline Bus5 & -0.7 & +0.3 & -2.4 & -0.03 & +0.1 & +0.4 & +1.4 & +0.01 & 0 \\
\hline Bus6 & -0.7 & +0.31 & +1.2 & +5.05 & -0.08 & +0.3 & +2.2 & +0.01 & 0 \\
\hline Bus8 & -0.7 & +0.25 & 0 & +0.1 & +5.67 & +0.5 & +0.6 & +0.01 & 0 \\
\hline Bus9 & -0.01 & -0.12 & -0.09 & +0.091 & -0.07 & +0.07 & +0.03 & +0.01 & 0 \\
\hline Bus10 & -0.6 & +0.29 & +1.5 & -0.05 & +0.08 & +0.3 & +2.5 & +0.01 & 0 \\
\hline Bus19 & -0.6 & +0.31 & -0.1 & +0.12 & +0.12 & +0.3 & +0.3 & +0.03 & +0.01 \\
\hline Bus20 & -0.6 & +0.33 & -0.2 & +0.12 & +0.12 & +0.3 & +0.3 & +0.02 & +0.02 \\
\hline
\end{tabular}

\section{CONCLUSION}

According to above the results, the followings are concluded, Intelligent Fuzzy set technique has an important advantage compared with the traditional method indicated as follows: It is an intelligent method based on fuzzy rules (if-then statements). It can identify the weakest bus at steady-state conditions and transient conditions during high load and fault, respectively, but the traditional method is utilized during fault conditions only. From the obtained results, it is clear that Fuzzy technique yields the same results in both steady-state and fault conditions which enable the use of the same technique with large systems and applying the method in steady-state conditions to get the most vulnerable bus in both steady-state and fault. Accordingly, Fuzzy technique is easier, faster and more accurate with increasing the number of memberships. Reducing the deviation value for the load buses parameters ( $\mathrm{P}$ and $\mathrm{Q}$ ), may reach zero, when applying SVC and STATCOM devices respectively at the optimum location (Bus 9 in this paper) during fault which means that, the system returned to stability conditions. The degree of reduction in deviation values during applying STATCOM, s more than when SVC, that means it is better than SVC for in terms of maintaining the stability of the system. When the fault occurs at Bus 20 has more than affected on the system because it is the strong bus.

\section{REFERENCES}

[1] Mohammad Rafee Shaik, A. Srinivasula Reddy. "Optimal placement and sizing of FACTS device to overcome contingencies in power systems." 2016 IEEE International Conference on Signal Processing, Communication, Power and Embedded System (SCOPES), pp. 838-842, June 2017.

[2] Abubakar Siddique, Yonghai Xu, Waseem Aslam and Muhammad Rasheed. "A Comprehensive Study on FACTS Devices to Improve the Stability and Power Flow Capability in Power System.” 2019 IEEE Asia Power and Energy Engineering Conference (APEEC), pp. 199-205, May 2019.

[3] Hajer Jmii, Asma Meddeb and Souad Chebbi. "An approach for improving voltage stability by combination of SVC and TCSC," 2016 IEEE 7th International Conference on Sciences of Electronics, Technologies of Information and Telecommunications (SETIT), pp.134-141, June 2017.

[4] Gagari Deb, Kabir Chakraborty and Sumita Deb. "Voltage stability analysis using reactive power loading as indicator and its improvement by FACTS device." 2016 IEEE 1st International Conference on Power Electronics, Intelligent Control and Energy Systems (ICPEICES), pp.1-5, Feb 2017. 
[5] J. Lakkireddy, R. Rastgoufard, I. Leevongwat and P. Rastgoufard. "Steady state voltage stability enhancement using shunt and series FACTS devices." 2015 IEEE Clemson University Power Systems Conference (PSC), May 2015.

[6] Ahmed Mustafa Mohammed. "Improving the voltage stability of electrical power systems using shunt FACTS devices.” master thesis, Faculty of Engineering, Cairo University Giza, Egypt, June 2009.

[7] Sami Repo. "On-Line Voltage Stability Assessment of Power System An-Approach of Black-box Modeling." PHD thesis, Tampere University of technology and the academy, Finland, 2001.

[8] Ashish Kumar Choubey, Prof.Arti Bhandakkar and Shri Ram. "Stability Improvement of Power System by Using Fuzzy Coordinated Static Var Compensator." International Journal of Engineering Trends and Technology (IJETT), vol. 25, no. 1, July 2015.

[9] Bindeshwar Singh, Prabhakar Tiwari and S. N. Singh. "Enhancement of Power System Performances by Optimally Placed FACTS Controllers by using Different Optimization Techniques in Distribution Systems." IEEE Uttar Pradesh Section International Conference on Electrical, Electronics and Computer Engineering (UPCON), Gorakhpur, Jan 2019.

[10] Sridhar Babu Gurijala, K S Srikanth, Ramchandra Nittala and G. Rohit Reddy. "Transmission system regularization with 5-level cascaded IPFC." International Journal of Power Electronics and Drive System (IJPEDS), vol. 10, No. 3, pp. 1437-1445, Sep 2019.

[11] Praveen Kumar Agrawal, Sangeeta DebBarman and Arun Shekhawat. "Fact Devices Implementation in Improvement of Power System Stability." SSRG International Journal of Electrical and Electronics Engineering (SSRG-IJEEE), vol. 3, May 2016.

[12] Bouanane Abdelkrim, Yahiaoui Merzoug. "Robust stability power in the transmission line with the use of a UPFC system and neural controllers based adaptive control." International Journal of Power Electronics and Drive System (IJPEDS), vol. 10, no. 3, pp. 1281-1296, Sep 2019.

[13] S.K Mishra, S.C Swain, L.N Tripathy. "Fault Detection \& Classification in UPFC Integrated Transmission Line Using DWT." International Journal of Power Electronics and Drive System (IJPEDS), vol. 8, no.4, pp. 1793-1803, Dec 2017.

[14] A. Sode-Yome, N. Mithulananthan and Kwang Y. Lee. "A Comprehensive Comparison of FACTS Devices for Enhancing Static Voltage Stability.” IEEE Power Engineering Society General Meeting, pp. 1-8, June 2007.

[15] Arthit Sode-Yome, Nadarajah Mithulananthan and Kwang Y. Lee. "Static Voltage Stability Margin Enhancement Using STATCOM, TCSC and SSSC." IEEE/PES Transmission and Distribution Conference \& Exhibition: Asia and Pacific Dalian, pp. 1-6, 2005.

[16] Unnati P. Prajapati, Priyank R. Bhavsar. "Improvement of power system security by optimal location of FACTs devices using sensitivity approach.” 2017 IEEE 8th International Conference on Computing, Communication and Networking Technologies (ICCCNT), Dec 2017.

[17] Arthur S. Lima, Italo G. Fernandes and Sidney Cerqueira. "A Fuzzy-based Controller for Interconnected Systems voltage regulation through FACTS devices." IEEE PES Innovative Smart Grid Technologies Conference, Nov 2019.

[18] Waseem Aslam, Yonghai Xu, Abubakar Siddique, Amir Nawaz and Muhammad Rasheed. "Electrical Power System Stability Enhancement by Using an Optimal Fuzzy PID Controller for TCSC with Dual TCRs." IEEE 3rd International Conference on Integrated Circuits and Microsystems (ICICM), Dec 2018.

[19] Saeed, A. T., Taha, M. Q., \& Abdullah, K. A. "Tracking technique for the sudden change of PV inverter load." International Journal of Power Electronics and Drive Systems, vol. 10, no. 4, p. 2076, 2019.

[20] Husham Idan Hussein, Ghassan Abdullah Salman and Mohammed Saadi Hasan. "Phase Measurement Units based FACT's Devices for the Improvement of Power Systems Networks Controllability." International Journal of Electrical and Computer Engineering (IJECE), vol. 8, no. 2, pp. 888-899, April 2018.

[21] Lalit Kumar, Dr. Sanjay Kumar, Sushil Kumar Gupta and Brijesh Kumar Raw. "Optimal Location of FACTS Devices for Loadability Enhancement using Gravitational Search Algorithm." 2019 IEEE 5th International Conference for Convergence in Technology (I2CT), pp. 1-5, March 2020.

[22] M. Benmeziane, S. Zebirate, A. Chaker1 and Z. Boudjema. "Fuzzy sliding mode control of doubly-fed induction generator driven by wind turbine." International Journal of Power Electronics and Drive System (IJPEDS), vol. 10, no. 3, pp. 1592-1602, Sep 2019.

[23] Abubakar Siddique, Yonghai XU, Waseem Aslam, Abdul Rehman and M. Kaleem Aslam. "Performance of Fuzzy Logic Based Controller for UPFC on Power Quality Issues in Transmission Network." 2018 IEEE International Conference on Power System Technology (POWERCON), pp. 2867-2872, Jan 2019.

[24] Hameed, Jamal A., Amer T. Saeed, and Mugdad H. Rajab. "Design and analysis of hydroelectric generation using waterwheel." 2018 9th International Renewable Energy Congress (IREC). IEEE, 2018.

[25] A Shobha Shankar, Dr. T. Ananthapadmanabha. "Fuzzy Approach to Critical Bus Ranking Under Normal and Line Outage Contingencies." International Journal on Soft Computing (IJSC), vol. 2, No. 1, pp. 59 - 69, Feb 2011.

[26] M. Chebbo, M.R. Irving and M J H Sterling. "Voltage Collapse Proximity Indicator: Behaviour and Implications." IEE Proceedings-C, vol. 139, pp. 241-252, May 1992 


\section{BIOGRAPHIES OF AUTHORS}
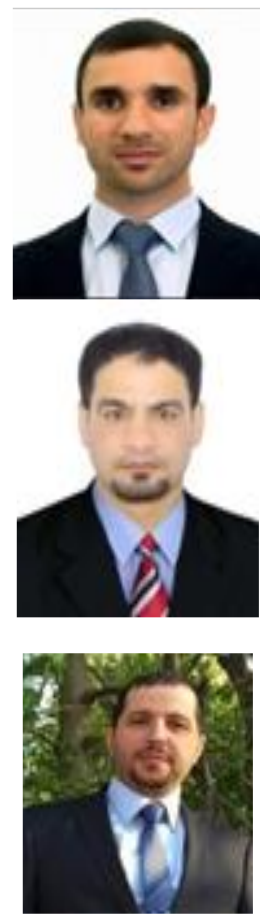

Jawad Hamad Hmeed, He is a lecturer at department of petroleum system control, Tikrit University, Iraq. He has a master degree from the Arabic Academic for science and Technology University, Egypt. He has published several papers during the past years

Hameed Ali Mohammed, He is a lecturer and head of department of petroleum system control, Tikrit University, Iraq. He has a master in control engineering from university of Mosul, Iraq. He has published several papers during the past years.

Amer T. Saeed, He is an instructor at Tikrit University. He has a master's degree from university of New Haven, USA in 2016. He has published several papers in high reputed journals and conferences. His main research area includes: Electrical Engineering, Networking and Communication Engineering. 